\title{
In-situ Synthesis and Characterization of Ceramic Reinforced Inconel 718 Coatings Using B4C-Inconel 718 Powders by Laser Directed Laser Energy Deposition
}

\author{
Yunze Li \\ Texas Tech University \\ Dongzhe Zhang \\ Texas Tech University \\ Bo Zhao \\ Texas Tech University \\ Weilong Cong ( $\nabla$ weilong.cong@ttu.edu ) \\ Texas Tech University https://orcid.org/0000-0001-6308-7383
}

\section{Research Article}

Keywords: Coating, Laser directed energy deposition (DED), Inconel 718 alloy, B4C, In-situ synthesis, Mechanical properties

Posted Date: January 10th, 2022

DOI: https://doi.org/10.21203/rs.3.rs-1230179/v1

License: (c) (i) This work is licensed under a Creative Commons Attribution 4.0 International License. Read Full License

Version of Record: A version of this preprint was published at The International Journal of Advanced Manufacturing Technology on March 28th, 2022. See the published version at https://doi.org/10.1007/s00170-022-09069-4. 


\section{Abstract}

Inconel 718 has been widely used in aerospace, nuclear and marine industries due to excellent hightemperature mechanical properties and corrosion resistance. In recent years, laser directed energy deposition (DED) become a competitive method in the fabrication of Inconel 718 coatings. Compared with other surface coating processes, laser DED has the advantage of extremely fine-grained structures, strong metallurgical bonding, and high density. However, the hardness and wear resistance of Inconel 718 coatings still need to be improved. To further improve these properties, ceramic reinforced Inconel 718 coatings have been investigated. Compared with ex-situ ceramic reinforcements, the in-situ synthesized reinforcements have the advantage of refined ceramic particle size, uniform distribution, and low thermal stress. $\mathrm{B}_{4} \mathrm{C}$ was a preferable additive material to fabricate in-situ synthesized multi-component ceramic reinforced Inconel 718 coatings. The addition of $\mathrm{B}_{4} \mathrm{C}$ could form a large number of borides and carbides as ceramic reinforcements. In addition, the in-situ reactions between Inconel 718 and $\mathrm{B}_{4} \mathrm{C}$ could release heat during the fabrication, thereby promoting the melting of material powders. However, there are currently no investigations on the in-situ synthesis mechanisms, microstructure, and mechanical properties of laser DED fabricated $\mathrm{B}_{4} \mathrm{C}$-Inconel 718 coatings. In this study, the effects of $\mathrm{B}_{4} \mathrm{C}$ on the properties of Inconel 718 coatings were investigated. Results show that $\mathrm{Ni}_{3} \mathrm{~B}, \mathrm{NbB}$, and $\mathrm{Cr}_{3} \mathrm{C}_{2}$ phases were formed. With the addition of $\mathrm{B}_{4} \mathrm{C}$, the size of Laves phase was refined and the porosity was decreased. The hardness and wear resistance of $\mathrm{B}_{4} \mathrm{C}$ reinforced coatings were improved by about $34 \%$ and $28 \%$, respectively.

\section{Introduction}

Inconel 718, as a kind of nickel-based superalloy, has remarkably high-temperature mechanical properties and corrosion resistance. It is a good choice for strengthening or repairing the structural parts that are prone to be damaged under conditions with complicated stress and elevated temperature [1,2]. In recent years, laser-directed energy deposition (DED) becomes a competitive technology for repairing and coating structural parts, due to its advantages of excellent bonding quality, easy controllability, excellent stability, and the capability of functionally gradient materials fabrication $[3,4]$. Due to these advantages, the fabrication of Inconel 718 coatings on stainless steel and nickel-based alloys by laser DED process have been received extensive research attention $[5,6]$. Results show that the laser DED fabricated coatings are free of micropores and micro-cracks and have good adherence to the substrates. However, the microhardness and wear resistance of laser DED fabricated Inconel 718 coatings is relatively low, which limited their further applications in many areas.

In order to improve the service life and mechanical properties of laser DED fabricated Inconel 718 coatings, ceramic materials such as $\mathrm{BN}, \mathrm{SiC}$, and $\mathrm{Al}_{2} \mathrm{O}_{3}$ have been directly added to Inconel 718 coatings as reinforcement phases [7-10]. However, the addition of ex-situ ceramic reinforcements also has a serious negative impact on the quality of coatings. Due to the high melting point of ex-situ ceramic reinforcements, the feedstock powders are hard to be fully melted. The un-melted particles could 
decrease the fluidity of the molten pool, leading to the generation of fabrication defects and the uneven distribution of the ceramic reinforcements [11]. In addition, the thermal expansion coefficients of ex-situ ceramic reinforcements and Inconel 718 matrix are different. During the solidification process, the matrix cracking in composites could be generated. Different from the ex-situ process, in the in-situ process, the reinforcements are synthesized in the matrix itself by chemical reactions. The ultra-fine ceramic reinforcement particles could be generated and uniformly distributed in the fabricated coatings, which could further improve the consistency and the mechanical properties of the fabricated coatings. In addition, the large thermal expansion coefficient differences between ceramic particles and matrix are reduced, which suppresses the crack generation $[12,13]$.

Over the past decade, researchers have demonstrated interest in the fabrication of in-situ synthesized ceramic reinforced Inconel 718 coatings. TiC has been the most commonly used as the reactant of in-situ synthesized ceramic reinforced Inconel 718 coatings [14]. Results show that a large number of sub-grain boundaries appear in the TiC/Inconel 718 nanocomposite coatings, which significantly increases the hardness and wear resistance. Compared with $\mathrm{TiC}, \mathrm{B}_{4} \mathrm{C}$ has more advantages to serve as the reactant of in-situ synthesized ceramic reinforced Inconel 718 coatings. Firstly, due to the low molar mass of $\mathrm{B}_{4} \mathrm{C}, \mathrm{a}$ small amount of $\mathrm{B}_{4} \mathrm{C}$ could form a large number of borides and carbides as hard phases that can significantly improve the hardness and the erosion resistance of the coating. Secondly, the borides generate from the reactions between $\mathrm{B}_{4} \mathrm{C}$ and Inconel 718 could provide heterogeneous nucleation sites for the Laves phase during the solidification, which could refine the size of Laves phase and improve the microhardness of the fabricated coatings. Finally, the in-situ reactions between $\mathrm{B}_{4} \mathrm{C}$ and metallic materials always generate a large amount of heat [15]. The generated heat has the potential to be utilized to promote the melting of feedstock powders and reduce the laser energy input. As far as the authors know, there are no investigations on the fabrication of in-situ synthesized ceramic reinforced Inconel 718 coatings using $\mathrm{B}_{4} \mathrm{C}$-Inconel 718 powders. The in-situ synthesis and characterization of the fabricated coatings are still unknown. In this study, the multi-component ceramic reinforced Inconel 718 coatings were successfully fabricated by laser DED process. The effects of $B_{4} C$ on molten pool size and temperature, element and phase compositions, microstructure, porosity, and mechanical properties of the fabricated coatings (including microhardness and wear resistance) were investigated.

\section{Experimental Procedures}

\subsection{Powder treatment}

The powder materials used in this study were $\mathrm{B}_{4} \mathrm{C}$ powder ( $99.7 \%$ purity) (Atlantic Equipment Engineers Inc., Upper Saddle River, NJ, USA) and Inconel 718 powders (99.7\% purity) (Carpenter Powder Products Inc., Bridgeville, PA, USA). A stainless steel 304 of $6.65 \mathrm{~mm}$ thickness was used as the substrate. The feedstock material powders (Inconel 718 and Inconel $718+2 w t . \% \mathrm{~B}_{4} \mathrm{C}$ ) were adopted to fabricate coatings. As shown in Figure 1, before the LDED process, $\mathrm{B}_{4} \mathrm{C}$ powder and Inconel 718 powder were mixed by a planetary ball milling machine (ND2L, Torrey Hills Technologies LLC., San Diego, CA, USA) for 
four hours with the rotation speed of $200 \mathrm{rpm}$. The weight ratio of milling balls to powders was $1: 1 . \mathrm{B}_{4} \mathrm{C}$ powders were mixed with Inconel 718 powders after the ball milling process.

\subsection{Experiment setup}

As shown in Figure 2, experiments were conducted on an LDED machine (LENS 450, Optomec Inc., Albuquerque, NM, USA) equipped with a 400 W fiber laser source (YLM-1070, IPG Photonics, USA). Before the fabrication, to avoid the oxidization of $\mathrm{B} 4 \mathrm{C}$ and $\mathrm{Ti}$ at a high temperature, argon gas was utilized to purge the chamber system. During the fabrication, the laser beam was generated and transformed to the substrate to generate a molten pool, which caught and melted the material powders. When the laser beam moved away, the molten pool was solidified to fabricate the first layer. After the fabrication of the first layer, the cladding head moved up the distance of a layer thickness to fabricate the second layer on the top surface of the first layer. By repeating this procedure, the coatings were fabricated layer by layer. The values or ranges of input fabrication variables are listed in Table 1.

\subsection{Measurement procedures}

During the fabrication, An infrared thermal camera (PYROVIEW 768 N, DIAS INC, Dresden, Germany) was used to obtain the thermal images of the molten pool. The infrared thermal camera was fixed in the chamber at a $20 \mathrm{~cm}$ distance to the molten pool. The professional software (PYROSOFT 3.22, DIAS INC, Dresden, Germany) was used to record the collected thermal data with a sample rate of $25 \mathrm{~Hz}$. The phases of the fabricated coatings were analyzed by an X-ray diffraction (XRD) machine (Ultima III, Rigaku

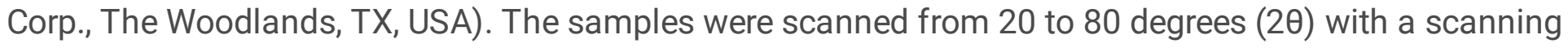
step of 0.02 degrees $(2 \theta)$, and the parameter in XRD tests are wavelength $0.154 \mathrm{~nm}$, voltage $40 \mathrm{kV}$, and current $44 \mathrm{~mA}$. Each peak was fitted by the MDI/JADE software (Version 2020, Materials Data, Livermore, CA, USA). A scanning electron microscope (SEM) (Crossbeam 540, Carl Zeiss AG, Oberkochen, Germany) was used to observe the microstructure morphologies of the fabricated coatings. An energy dispersive Xray spectroscopy (EDS) system equipped was used to analyze the element compositions. Before the observation, a thin Iridium layer was coated on the samples to create excellent conductivity and the signal to noise ratio dramatically, resulting in crisp and clear SEM images. To further quantify the size and volume content of the reinforcements, the Image $\mathrm{J}$ software was utilized to process the SEM images for both Inconel 718 coatings and $\mathrm{B}_{4} \mathrm{C}$-Inconel 718 coatings under the mode of black and white. The volume fraction of Laves phase is quantified by the area ratio of Laves phase in the cross-sectional surface. To obtain an accurate result, for both Inconel 718 coatings and $\mathrm{B}_{4} \mathrm{C}$-Inconel 718 coatings, five cross-sectional surfaces were analyzed to get the average volume fractions of Laves phases.

The microhardness of the deposited coating layers was tested by a Vickers microhardness tester (Phase II, Upper Saddle River, NJ, USA) with a $10 \mathrm{~N}$ normal load. Two samples fabricated by the LDED process were tested to measure the microhardness. For each sample, the microhardness test was performed ten times on random positions of the polished surface. The wear rate was tested and measured by dry sliding tests with a silicon carbide ball at room temperature using a mechanical testing system (PB1000, 
Nanovea, Manufacturer in Irvine, CA, USA). During the dry sliding test, the SiC ball was sliding on the surface of the coating for 15 minutes with a load of $0.2 \mathrm{~N}$, a constant sliding speed of $3 \mathrm{~mm} / \mathrm{s}$, and a sliding distance of $3 \mathrm{~mm}$. An OLYMPUS DSX-510 optical microscope (OM) (Tokyo, Japan) was used to observe the worn surface and obtain the scratching width after the dry sliding tests. The wear rate $W_{r}$ was calculated by Eq.1.

$$
W_{r}=\frac{V}{F(v T)}
$$

where, $V$ was the wear volume lost, $\mathrm{mm}^{3}, F$ was the normal load, $\mathrm{N} ; v$ was the sliding speed, $\mathrm{mm} / \mathrm{s} ; T$ was the duration time, $s$.

\section{Results And Discussion}

\subsection{Phase composition}

Figure 3 shows the XRD results of the phase composition analysis on Inconel 718 coatings and $\mathrm{B}_{4} \mathrm{C}$ Inconel 718 coatings. In the XRD results of Inconel 718 coatings, the peaks matched up reasonably well for a y Ni-Cr-Fe phase (PDF-\# 65-0380) but were shifted to the left slightly. Most likely there were a small amount of other $\mathrm{Nb}$-rich and Mo-rich precipitations doped into the structure. Similar results were also reported in the laser DED fabricated Inconel 718 parts $[16,17]$. With the addition of $B_{4} C$, some new phases include $\mathrm{Ni}_{3} \mathrm{~B}$ (PDF-\# 48-1223), NbB (PDF-\# 32-0709), and $\mathrm{Cr}_{2} \mathrm{C}_{3}$ (PDF-\# 65-0897) were identified by the $X R D$ analysis. In addition, there was no peak representing $B_{4} C$ in the XRD results. It could be confirmed that the feedstock $B_{4} C$ powders were completely reacted with Inconel 718 to form multi-component ceramic reinforcements during the fabrication. Inconel 718 as a kind of nickel-chromium alloy also contained significant amounts of niobium, iron, and molybdenum along with lesser amounts of aluminum and titanium. Because of the instability of $\mathrm{B}_{4} \mathrm{C}$ in liquid metallic materials, there were in-situ reactions to form $\mathrm{Ni}_{3} \mathrm{~B}, \mathrm{NbB}$, and $\mathrm{Cr}_{3} \mathrm{C}_{2}$ phases:

$$
12 \mathrm{Ni}+4 \mathrm{Nb}+3 \mathrm{Cr}+2 \mathrm{~B}_{4} \mathrm{C} \rightarrow 4 \mathrm{Ni}_{3} \mathrm{~B}+4 \mathrm{NbB}+\mathrm{Cr}_{3} \mathrm{C}_{2}
$$

It could also be seen that compared with Inconel 718 coatings, the intensity of the Ni-Cr-Fe peaks in $\mathrm{B}_{4} \mathrm{C}$ Inconel 718 coatings was slightly decreased. The major reason was that $\mathrm{Ni}$ and $\mathrm{Cr}$ reacted with $\mathrm{B}_{4} \mathrm{C}$ to form ceramics during the fabrication, reducing the content of $\mathrm{Ni}-\mathrm{Cr}-\mathrm{Fe}$. The positions of $\mathrm{Ni}-\mathrm{Cr}-\mathrm{Fe}$ peaks in $\mathrm{B}_{4} \mathrm{C}$-Inconel 718 coatings were further shifted to the left, which was farther to the positions of the standard $\mathrm{Ni}-\mathrm{Cr}-\mathrm{Fe}$ phase. The peak shift indicated that the content of $\mathrm{Nb}$-rich and Mo-rich precipitations (Laves phase) in $\mathrm{B}_{4} \mathrm{C}-$-Inconel 718 coatings was higher than that in Inconel 718 coatings.

\subsection{Molten pool size and temperature}


The thermal image of the molten pool for the 3 layers single track coatings $(t=25 \mathrm{~s})$ and the maximum temperature during the fabrication are shown in Figure 4. As shown in Figure 4(a), the shape of both Inconel 718 coatings and $\mathrm{B}_{4} \mathrm{C}$-Inconel 718 coatings was an irregular circle, when taking the melting point of the Inconel $718\left(1450^{\circ} \mathrm{C}\right)$ as the molten pool boundaries. With the same laser deposition input parameters of laser power, hatch distance, scanning speed, and powder feed rate, the molten pool size of $\mathrm{B}_{4} \mathrm{C}$-Inconel 718 coatings $(\sim 2.25 \mathrm{~mm})$ was much larger than that of Inconel 718 coatings $(\sim 1.35 \mathrm{~mm})$. As shown in Figure 4(b), the maximum temperature of Inconel 718 coatings was slightly increased from $1700{ }^{\circ} \mathrm{C}$ to $1800^{\circ} \mathrm{C}$ during the fabrication due to the heat accumulation effects. As a comparison, the maximum temperature of $\mathrm{B}_{4} \mathrm{C}$-Inconel 718 coatings was much higher than Inconel 718 coatings, which were significantly increased from $1900^{\circ} \mathrm{C}$ to $2200^{\circ} \mathrm{C}$ during the fabrication. The higher temperature increasing rate and the higher maximum temperature of $\mathrm{B}_{4} \mathrm{C}$-Inconel 718 coatings indicated that the insitu reactions between $\mathrm{B}_{4} \mathrm{C}$ and Inconel 718 released a large amount of heat [15]. A larger molten pool size and higher molten pool temperature had the potential to increase the fluidity of the liquid materials in the molten pool, which could improve the bonding quality, coating density, and reinforcement distribution.

\subsection{Element composition and microstructure}

\subsubsection{Analysis of element composition}

Figure 5 shows the element compositions of Inconel 718 coatings and B4C-Inconel 718 coatings. In Inconel 718 coatings, there were white regions distributed in a grey matrix. Point 1 and point 2 were probed in the white regions and grey matrix regions, respectively. The element compositions of the white regions and grey matrix regions were shown in Table 2(a). Both white regions and grey matrix regions were rich in $\mathrm{Ni}, \mathrm{Cr}$, and $\mathrm{Fe}$. Compared with grey matrix regions, white regions had a higher content of $\mathrm{Nb}$ and Mo and represented the Laves phase, which was generated during the solidification process through the segregation of $\mathrm{Nb}$ and $\mathrm{Mo}$ from the matrix $[18,19]$. The grey matrix regions were $\mathrm{Ni}-\mathrm{Cr}-\mathrm{Fe}$ phase, in which the contents of $\mathrm{Nb}$ and Mo were lower than that in feedstock Inconel 718 powders. The reason was that the formation of Laves phase consumed the solid solution elements of $\mathrm{Nb}$ and $\mathrm{Mo}$ in the matrix.

Different from the Inconel 718 coatings, there were three kinds of regions in $\mathrm{B}_{4} \mathrm{C}$-Inconel 718 coatings. Besides the white precipitated regions and the grey matrix regions, there were also irregular black regions distributed near the white regions. The size and morphology of black regions were different from the feedstock $\mathrm{B}_{4} \mathrm{C}$ powders, which could be considered as the in-situ synthesized ceramic reinforcement. As discussed in Section 3.1, during the fabrication, there were in-situ reactions between $\mathrm{B}_{4} \mathrm{C}$ and Inconel 718 to form $\mathrm{Ni}_{3} \mathrm{~B}, \mathrm{NbB}$, and $\mathrm{Cr}_{3} \mathrm{C}_{2}$. To further investigate the composition of the in-situ synthesized ceramic reinforcement, point 1 and point 2 were probed in the black regions and grey matrix, respectively. The detailed element compositions of different regions were shown in Table 2(b). In the black regions, the major elements were $\mathrm{Ni}, \mathrm{B}, \mathrm{Cr}$, and $\mathrm{C}$. Compared with the grey matrix regions, the black regions had higher element content of $\mathrm{B}$ and $\mathrm{C}$, indicating the black regions were mainly borides and carbides that were 
formed through the reactions between $\mathrm{B}_{4} \mathrm{C}$ and Inconel 718. Combined with the XRD results, the black regions could be confirmed as the in-situ synthesized ceramic reinforcements of $\mathrm{Ni}_{3} \mathrm{~B}, \mathrm{NbB}$, and $\mathrm{Cr}_{2} \mathrm{C}_{3}$.

\subsubsection{Analysis of microstructural morphology}

Figure 6(a) shows the comparisons on microstructural morphologies of Inconel 718 coatings and $\mathrm{B}_{4} \mathrm{C}$ Inconel 718 coatings fabricated by laser DED process. In Inconel 718 coatings, it could be seen that the growth of long strip-shaped precipitated Laves phase was in the building direction (vertical direction). This phenomenon was caused by the unidirectional solidification direction. During the fabrication of Inconel 718 coatings and $\mathrm{B}_{4} \mathrm{C}$-Inconel 718 coatings by the laser DED process, the localized heat flux within the molten pool was the main factor influencing the grain growth, which was usually vertical downward due to the good thermal conductivity of Ti substrates [2]. The gradient of temperature in the vertical direction was higher than that in the horizontal direction, leading to the bottom-up generation of Laves phase.

With the addition of $\mathrm{B}_{4} \mathrm{C}$, the in-situ formed ceramic reinforcements were generated along with the precipitated Laves phase. The ceramic reinforcements and Laves phase were uniformly distributed in laser $\mathrm{DED}$ fabricated $\mathrm{B}_{4} \mathrm{C}$-Inconel 718 coatings. The formation mechanism could be in three stages:

Firstly, the laser beam melted the substrates and generated a molten pool. As discussed in Section 3.1, the temperature of the molten pool reached the melting point of $\mathrm{B}_{4} \mathrm{C}$ during the fabrication. Both $\mathrm{B}_{4} \mathrm{C}$ and Inconel 718 powders were fully melted to form the liquid-state mixture. The added $B$ element would react with part of liquid $\mathrm{Nb}$ and $\mathrm{Ni}$ constituent to form liquid $\mathrm{NbB}$ and $\mathrm{Ni}_{3} \mathrm{~B}$.

Secondly, when the laser beam moved away, the liquid materials in the molten pool cooled down and started to be solidified. In the beginning, due to the high melting point, $\mathrm{NbB}$ and $\mathrm{Ni}_{3} \mathrm{~B}$ precipitated and grew into long strip particles, which provided nucleation sites for the Laves phase. Then, the Laves phase nucleated around the ceramics in the liquid Ni-Cr-Fe.

Finally, the liquid Ni-Cr-Fe solidified to generate the matrix. The in-situ formed ceramics and precipitated Laves phase were uniformly distributed in the Ni-Cr-Fe matrix.

To further investigate the morphology, size, and volume fraction of precipitated Laves phase, the SEM images under the mode of black (matrix and ceramic reinforcement) and white (precipitated Laves phase) were shown in Figure $6(\mathrm{~b})$. With the addition of $\mathrm{B}_{4} \mathrm{C}$, the size of precipitated Laves phase in $\mathrm{B}_{4} \mathrm{C}$ Inconel 718 coatings was decreased. The major reason was that the element $B$ from the decomposition of $\mathrm{B}_{4} \mathrm{C}$ reacted with Inconel 718 and then formed boride particles, which could act as the active nuclei in the molten pool. A large number of active nuclei increased the number of precipitated Laves phase grains in a certain melting volume, which suppressed the growth of Laves phase into a coarse stripshaped structure during the solidification. It could be also seen that with the addition of $\mathrm{B}_{4} \mathrm{C}$, the volume fraction of Laves phase was significantly decreased from $17.742 \%$ to $6.396 \%$. The major reason was that 
the $\mathrm{Nb}$, an important constituent element of the laves phase, reacted with $\mathrm{B}_{4} \mathrm{C}$ to form $\mathrm{NbB}$ during the fabrication, resulting in the lower $\mathrm{Nb}$ content in the molten pool. As a result, the formation of Laves phase in $\mathrm{B}_{4} \mathrm{C}$-Inconel 718 coatings was suppressed. Similar results had been reported in the Inconel 625 with 0.4 wt.\% boron coatings fabricated by the gas tungsten arc deposition process [20].

\subsection{Fabrication Defects}

The effects of $\mathrm{B}_{4} \mathrm{C}$ on the fabrication defects of Inconel 718 coatings were shown in Figure 7. It can be seen that the irregular-shaped defects were distributed in the In Inconel 718 coatings. As a comparison, there was no irregular-shaped defect in the $\mathrm{B}_{4} \mathrm{C}$-Inconel 718 coatings. In the LDED process, the irregularshaped fabrication defects on the cross sectional surface were usually caused by the lack of fusion, as demonstrated by Zhang et al. [21]. Since the molten pool size and temperature of $\mathrm{B}_{4} \mathrm{C}$-Inconel 718 coatings were much larger than that of Inconel 718 coatings (as discussed in Section 3.1), more feedstock powders could be caught and fully melted by the molten pool. The formation of sufficient overlaps was promoted, which could reduce the lack of fusion at the boundaries of the molten pool.

It can be also seen that there were also some micropores distributed in both Inconel 718 coatings and $\mathrm{B}_{4} \mathrm{C}$-Inconel 718 coatings. In the laser DED process, the cooling rate was extremely high. Entrapped gas bubbles were difficult to be efficiently expelled before the molten pool solidified [22]. Compared with Inconel 718 coatings, the number of micropores in $\mathrm{B}_{4} \mathrm{C}$-Inconel 718 coatings was much smaller than that in Inconel 718 coatings. There were two major reasons. Firstly, due to the heat generated from the in-situ reactions between $\mathrm{B}_{4} \mathrm{C}$ and Inconel 718 , the molten pool of $\mathrm{B}_{4} \mathrm{C}$-Inconel 718 coatings had the thermodynamic conditions with higher fluidity. Gas bubbles could float upward faster and escape from the molten pool before the molten pool solidification. Secondly, the solidification process of $\mathrm{B}_{4} \mathrm{C}$-Inconel 718 coatings during the fabrication was extended by the exothermic reactions and the melting point depressant (B element), which could also promote the escape of gas bubbles[20].

\subsection{Analysis of mechanical properties}

\subsubsection{Microhardness}

Figure 8 shows the comparison of the microhardness of Inconel 718 coatings and $\mathrm{B}_{4} \mathrm{C}$-Inconel 718 coatings fabricated by laser DED process. The microhardness of $\mathrm{B}_{4} \mathrm{C}$-Inconel 718 coatings $(348 \mathrm{HV})$ was significantly higher than that of Inconel 718 coatings (264 HV). As discussed in Section 3.3, ceramic reinforcement particles were uniformly distributed in the Ni-Cr-Fe matrix. These reinforcements had higher hardness than Inconel 718 alloy, which could bear the load during the microhardness tests. In addition, it was well known that a large amount of Laves phase in the form of long-strip morphology was detrimental to the strength and hardness of Inconel 718 since it depletes the elements needed for precipitation strengthening. With the addition of $\mathrm{B}_{4} \mathrm{C}$, the coarse and long strip-shaped Laves phase was changed to needle-shaped Laves phase with refined size, uniformed distribution, and lower volume fraction. The negative impacts of Laves phase on mechanical properties of Inconel 718 coatings were 
greatly reduced. In addition, the microhardness was positively correlated to the density. As discussed in Section 3.4, with the addition of $\mathrm{B}_{4} \mathrm{C}$, the fabrication defects and micropores were significantly decreased, which increased the ability to support the load and improve the microhardness.

\subsubsection{Wear resistance}

Figure 9 shows the differences in the morphology of worn surfaces between the Inconel 718 coatings and $\mathrm{B}_{4} \mathrm{C}$-Inconel 718 coatings. In the dry sliding tests of Inconel 718 coatings, scratches and a large area of coating delamination can be observed on the worn surface of the Inconel 718 laser cladding layer. These features indicated that local cold welds between the coating surfaces and silicon balls occurred under a load. Such phenomenon always occurred in adhesive wear, which had been reported by Hurricks et al. [23]. In addition, some grooves could also be observed on the worn surface of Inconel 718 coatings, which occurred when a hard surface ( $\mathrm{SiC}$ ball) pass over a soft surface (Inconel 718 coatings). The wear mechanism of Inconel 718 coatings in the dry sliding tests was the combination of adhesive wear and abrasive wear. Compared with Inconel 718 coatings, the worn surface of laser DED fabricated $\mathrm{B}_{4} \mathrm{C}$-Inconel 718 coatings showed less delamination and smoother grooves. The major reason was that the high hardness of the $\mathrm{B}_{4} \mathrm{C}$-Inconel 718 coatings made it difficult for the silicon ball to penetrate into the surface. The morphologies of the worn surfaces indicated that the abrasive wear played a dominant role in the $\mathrm{B}_{4} \mathrm{C}$-Inconel 718 coatings.

Figure 10 shows the wear rate of Inconel 718 coatings and $\mathrm{B}_{4} \mathrm{C}$-Inconel 718 coatings. The wear rate of $\mathrm{B}_{4} \mathrm{C}$-Inconel 718 coatings was much smaller than that of Inconel 718 coatings, indicating a higher wear resistance. As discussed in Section 3.5.1, the microhardness of $\mathrm{B}_{4} \mathrm{C}$-Inconel 718 coatings was much higher than that of Inconel 718 coatings. According to Archard's wear equation, the volume of wear is inversely proportional to the hardness of the material. The higher hardness of $\mathrm{B}_{4} \mathrm{C}$-Inconel 718 coatings also had a great influence on the improvement of wear resistance. In addition, the metal matrix composite coatings with higher density always showed excellent wear resistance. Compared with Inconel 718 coatings, there were fewer fabrication defects in $\mathrm{B}_{4} \mathrm{C}$-Inconel 718 coatings, which was attributed to suppressing fracture and the spalling of hard particles and hard protuberances during the dry sliding test. Besides the effects of hardness and density on wear resistance, the wear mechanism also had great impacts on the wear resistance. The $\mathrm{B}_{4} \mathrm{C}$-Inconel 718 coatings with abrasive wear type had a smoother worn surface, which could reduce the coefficient of friction during the dry sliding test. Under the same test condition, the friction force was reduced, resulting in a smaller material removal volume and higher wear resistance.

\section{Conclusions}

In this study, the in-situ synthesized semicontinuous network microstructural ceramic reinforced Inconel 718 coatings were fabricated by laser DED process. The in-situ synthesis of the fabricated $\mathrm{B}_{4} \mathrm{C}$-Inconel 
718 coatings and the effects of $\mathrm{B}_{4} \mathrm{C}$ on the phase composition, microstructure, microhardness, and wear resistance were investigated. The major conclusions are drawn as follows:

1. During the laser $D E D$ process, there were reactions between $B_{4} C$ and Inconel 718 to form $\mathrm{Ni}_{3} B, N b B$, and $\mathrm{Cr}_{2} \mathrm{C}_{3}$. During the solidification, the needle-shaped $\mathrm{NbB}$ and $\mathrm{Ni}_{3} \mathrm{~B}$ whiskers were uniformly distributed in Inconel 718 matrix and provided nucleation sites for the Laves phase. With the addition of $\mathrm{B}_{4} \mathrm{C}$, the size and volume fraction of Laves phase were significantly reduced.

2. The in-situ reactions generated a large amount of heat. The molten pool temperature was significantly increased, which could suppress the formation of the lack of fusion defects and micropores in $\mathrm{B}_{4} \mathrm{C}$ Inconel 718 coatings.

3. With the addition of $\mathrm{B}_{4} \mathrm{C}$, the microhardness of $\mathrm{B}_{4} \mathrm{C}$-Inconel 718 coatings was significantly increased due to the generation of ceramic reinforcements and the refinement of Laves phase. The wear mechanism of $\mathrm{B}_{4} \mathrm{C}$-Inconel 718 coatings was abrasive wear, which was different from the Inconel 718 coatings (adhesive and abrasive wear). The wear resistance of $\mathrm{B}_{4} \mathrm{C}$-Inconel 718 coatings was higher than Inconel 718 coatings because of higher hardness, lower porosity, and smoother worn surface.

\section{Declarations}

Acknowledgments Not applicable

Funding The test of Raman spectroscopy in this study was supported by NSF CAREER Grant No. DMR1760668.

Conflict of interest The authors declare no competing interests.

Availability of data and material The data supporting the conclusions are included in the article.

Code availability Not applicable.

Authors' contributions Yunze Li: methodology, investigation, validation, writing-original draft. Dongzhe Zhang: investigation, writing-review and editing. Bo Zhao: investigation. Weilong Cong: writing-review and editing.

Ethics approval The authors confirm that they have abided by the publication ethics and state that this work is original and has not been used for publication anywhere before.

Consent to participate The authors are willing to participate in journal promotions and updates.

Consent for publication The authors give consent to the journal regarding the publication of this work.

\section{References}


[1] Ning, F., Hu, Y., Liu, Z., Cong, W., Li, Y., \& Wang, X. (2017). Ultrasonic vibration-assisted laser engineered net shaping of Inconel 718 parts: a feasibility study. Procedia Manufacturing, 10, 771-778.

[2] Wang, H., Hu, Y., Ning, F., \& Cong, W. (2020). Ultrasonic vibration-assisted laser engineered net shaping of Inconel 718 parts: Effects of ultrasonic frequency on microstructural and mechanical properties. Ceramics International, 276, 116395.

[3] Hu, Y., \& Cong, W. (2018). A review on laser deposition-additive manufacturing of ceramics and ceramic reinforced metal matrix composites. Ceramics International, 44(17), 20599-20612.

[4] Wang, L., Felicelli, S., Gooroochurn, Y., Wang, P., \& Horstemeyer, M. (2008). Optimization of the LENS ${ }^{\circledR}$ process for steady molten pool size. Materials Science Engineering: A, 474(1-2), 148-156.

[5] Tabernero, I., Lamikiz, A., Martínez, S., Ukar, E., \& Figueras, J. (2011). Evaluation of the mechanical properties of Inconel 718 components built by laser cladding. International Journal of Machine Tools Manufacture, 51(6), 465-470.

[6] Lambarri, J., Leunda, J., Navas, V. G., Soriano, C., \& Sanz, C. (2013). Microstructural and tensile characterization of Inconel 718 laser coatings for aeronautic components. Optics Lasers in Engineering, 51(7), 813-821.

[7] Kim, S. H., Shin, G.-H., Kim, B.-K., Kim, K. T., Yang, D.-Y., Aranas, C., . . Yu, J.-H. (2017). Thermomechanical improvement of Inconel 718 using ex situ boron nitride-reinforced composites processed by laser powder bed fusion. Scientific reports, 7(1), 1-13.

[8] Zemzemi, F., Rech, J., Salem, W. B., Dogui, A., \& Kapsa, P. (2014). Identification of friction and heat partition model at the tool-chip-workpiece interfaces in dry cutting of an Inconel 718 alloy with CBN and coated carbide tools. Advances in Manufacturing Science Technology, 38(1).

[9] Sahu, S. K., Jadam, T., Datta, S., \& Nandi, G. (2018). Effect of using SiC powder-added dielectric media during electro-discharge machining of Inconel 718 superalloys. Journal of the Brazilian Society of Mechanical Sciences Engineering, 40(7), 1-19.

[10] Yu, Z., Tan, H., Wang, S., Cheng, J., Sun, Q., Yang, J., \& Liu, W. (2020). High-temperature tribological behaviors of MoAIB ceramics sliding against $\mathrm{Al}_{2} \mathrm{O}_{3}$ and Inconel 718 alloy. Ceramics International, 46(10), 14713-14720.

[11] Zhang, D., Li, Y., Wang, H., \& Cong, W. (2021). An investigation on Ni4Ti3 phase precipitation and its effects in laser directed energy deposition of TiC-NiTi composites. Materials Science Engineering: A,809, 140976.

[12] Zhang, X., Song, F., Wei, Z., Yang, W., \& Dai, Z. (2017). Microstructural and mechanical characterization of in-situ $\mathrm{TiC} / \mathrm{Ti}$ titanium matrix composites fabricated by graphene/Ti sintering 
reaction. Materials Science Engineering: A, 705, 153-159.

[13] Xia, M., Liu, A., Hou, Z., Li, N., Chen, Z., \& Ding, H. (2017). Microstructure growth behavior and its evolution mechanism during laser additive manufacture of in-situ reinforced ( $\mathrm{TiB}+\mathrm{TiC}) / \mathrm{Ti}$ composite. Journal of Alloys Compounds, 728, 436-444.

[14] Muvvala, G., Karmakar, D. P., \& Nath, A. K. (2018). In-process detection of microstructural changes in laser cladding of in-situ Inconel 718/TiC metal matrix composite coating. Journal of Alloys Compounds, $740,545-558$.

[15] Zhao, Y., Yu, T., Sun, J., \& Jiang, S. (2020). Microstructure and properties of laser cladded $\mathrm{B}_{4} \mathrm{C} / \mathrm{TiC} / \mathrm{Ni}-$ based composite coating. International Journal of Refractory Metals Hard Materials,86, 105112.

[16] Liu, Y., Li, X., Li, Y., Zhao, Z., \& Bai, F. (2016). The lattice distortion of nickel particles generated by spark discharge in hydrocarbon dielectric mediums. Applied Physics A, 122(3), 174.

[17] Kaynak, Y., \& Tascioglu, E. (2018). Finish machining-induced surface roughness, microhardness and XRD analysis of selective laser melted Inconel 718 alloy. Procedia Cirp, 71, 500-504.

[18] Radhakrishna, C., \& Rao, K. P. (1997). The formation and control of Laves phase in superalloy 718 welds. Journal of Materials Science, 32(8), 1977-1984.

[19] Janaki Ram, G., Venugopal Reddy, A., Prasad Rao, K., \& Madhusudhan Reddy, G. (2004). Control of Laves phase in Inconel 718 GTA welds with current pulsing. Science technology of welding joining, 9(5), 390-398.

[20] Tian, Y., Ouyang, B., Gontcharov, A., Gauvin, R., Lowden, P., \& Brochu, M. (2017). Microstructure evolution of Inconel 625 with 0.4 wt\% boron modification during gas tungsten arc deposition. Journal of Alloys Compounds, 694, 429-438.

[21] Zhang, B., Li, Y., \& Bai, Q. (2017). Defect formation mechanisms in selective laser melting: a review. Chinese Journal of Mechanical Engineering, 30(3), 515-527.

[22] Li, Y., Zhang, D., Wang, H., \& Cong, W. (2021). Fabrication of a TiC-Ti Matrix Composite Coating Using Ultrasonic Vibration-Assisted Laser Directed Energy Deposition: The Effects of Ultrasonic Vibration and TiC Content. Metals, 11(5), 693.

[23] Hurricks, P. (1973). Some metallurgical factors controlling the adhesive and abrasive wear resistance of steels. A review. Wear, 26(3), 285-304.

\section{Tables}

Table 1. Laser coating parameters of $\mathrm{B}_{4} \mathrm{C}-$ Inconel 718 coatings 


\begin{tabular}{|ll|}
\hline Input fabrication variables & Values \\
\hline Laser power $(\mathrm{W})$ & 225 \\
\hline Beam diameter of laser $(\mu \mathrm{m})$ & 400 \\
\hline Wavelength of laser $(\mathrm{nm})$ & 1064 \\
\hline Deposit head scanning speed $(\mathrm{mm} / \mathrm{min})$ & 508 \\
\hline Hatch distance $(\mu \mathrm{m})$ & 340 \\
\hline Layer thickness $(\mu \mathrm{m})$ & 432 \\
\hline Powder feeding rate $(\mathrm{g} / \mathrm{min})$ & 2 \\
\hline Number of layers & 3 \\
\hline Argon gas flow rate $(\mathrm{L} / \mathrm{min})$ & 6 \\
\hline Scanning orientation $\left(^{\circ}\right)$ & $0,90,180,270$ \\
\hline
\end{tabular}

Table 2(a). Element composition of Inconel 718

\begin{tabular}{|lll|}
\hline Element & P1 Atomic percent (\%) & P2Atomic percent (\%) \\
\hline $\mathrm{Ni}$ & 47.31 & 45.95 \\
$\mathrm{Cr}$ & 20.46 & 24.84 \\
$\mathrm{Fe}$ & 15.56 & 21.50 \\
$\mathrm{Nb}$ & 9.95 & 3.47 \\
$\mathrm{Mo}$ & 5.16 & 3.34 \\
\hline $\mathrm{Ti}$ & 1.35 & 0.67 \\
\hline $\mathrm{Al}$ & 0.21 & 0.23 \\
\hline
\end{tabular}

Table 2(b). Element composition of $\mathrm{B}_{4} \mathrm{C}$-Inconel 718 


\begin{tabular}{|lll|}
\hline Element & P1 Atomic percent (\%) & P2 Atomic percent (\%) \\
\hline $\mathrm{Ni}$ & 29.63 & 51.40 \\
\hline $\mathrm{B}$ & 29.28 & - \\
\hline $\mathrm{Cr}$ & 17.36 & 18.04 \\
\hline $\mathrm{C}$ & 7.11 & 7.30 \\
\hline $\mathrm{Fe}$ & 6.55 & 19.55 \\
\hline $\mathrm{Nb}$ & 5.66 & 1.45 \\
\hline $\mathrm{Mo}$ & 2.91 & 1.40 \\
\hline $\mathrm{Ti}$ & 1.30 & 0.32 \\
\hline $\mathrm{Al}$ & 0.20 & 0.54 \\
\hline
\end{tabular}

Figures 


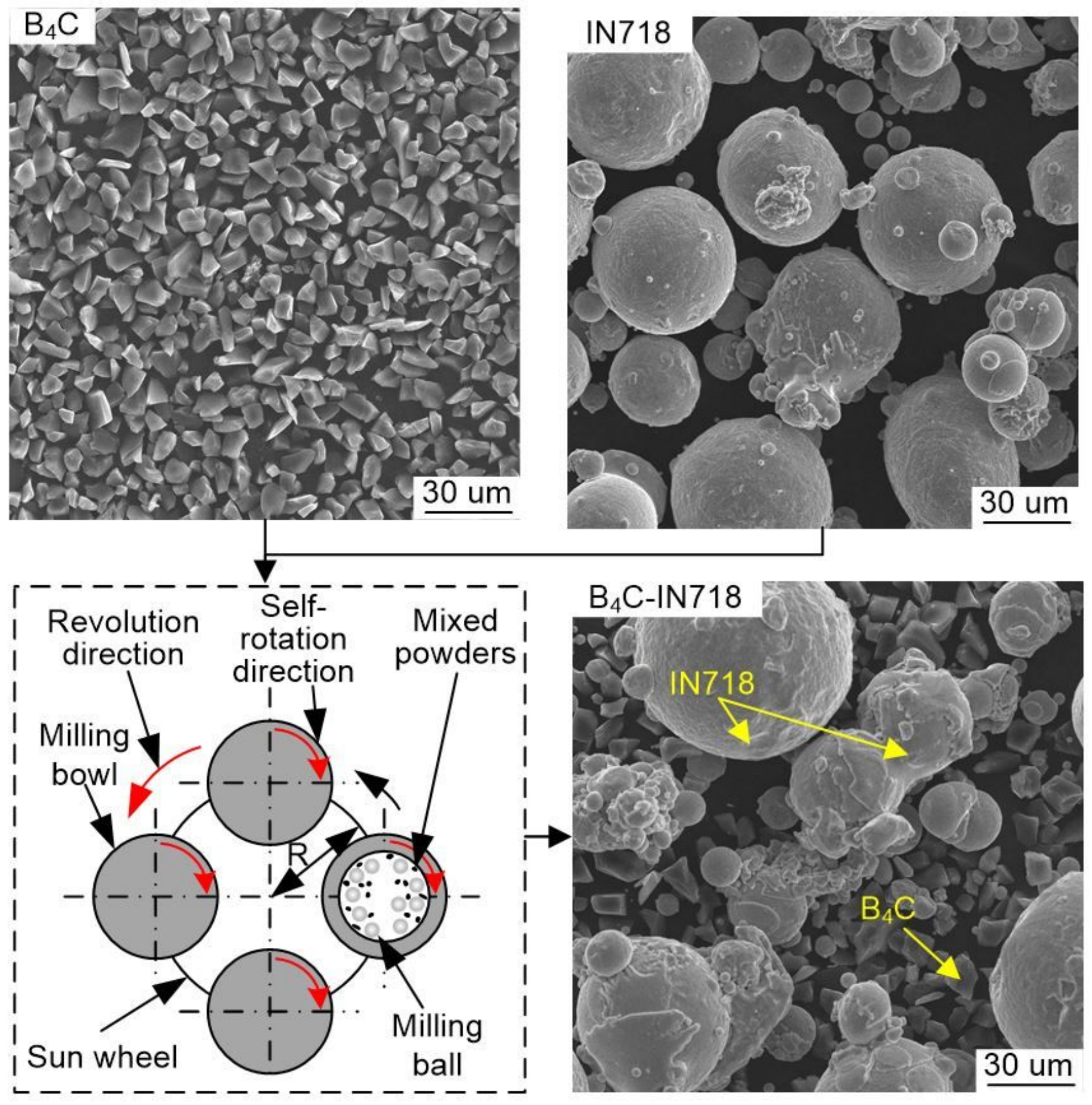

Figure 1

Powder treatment 


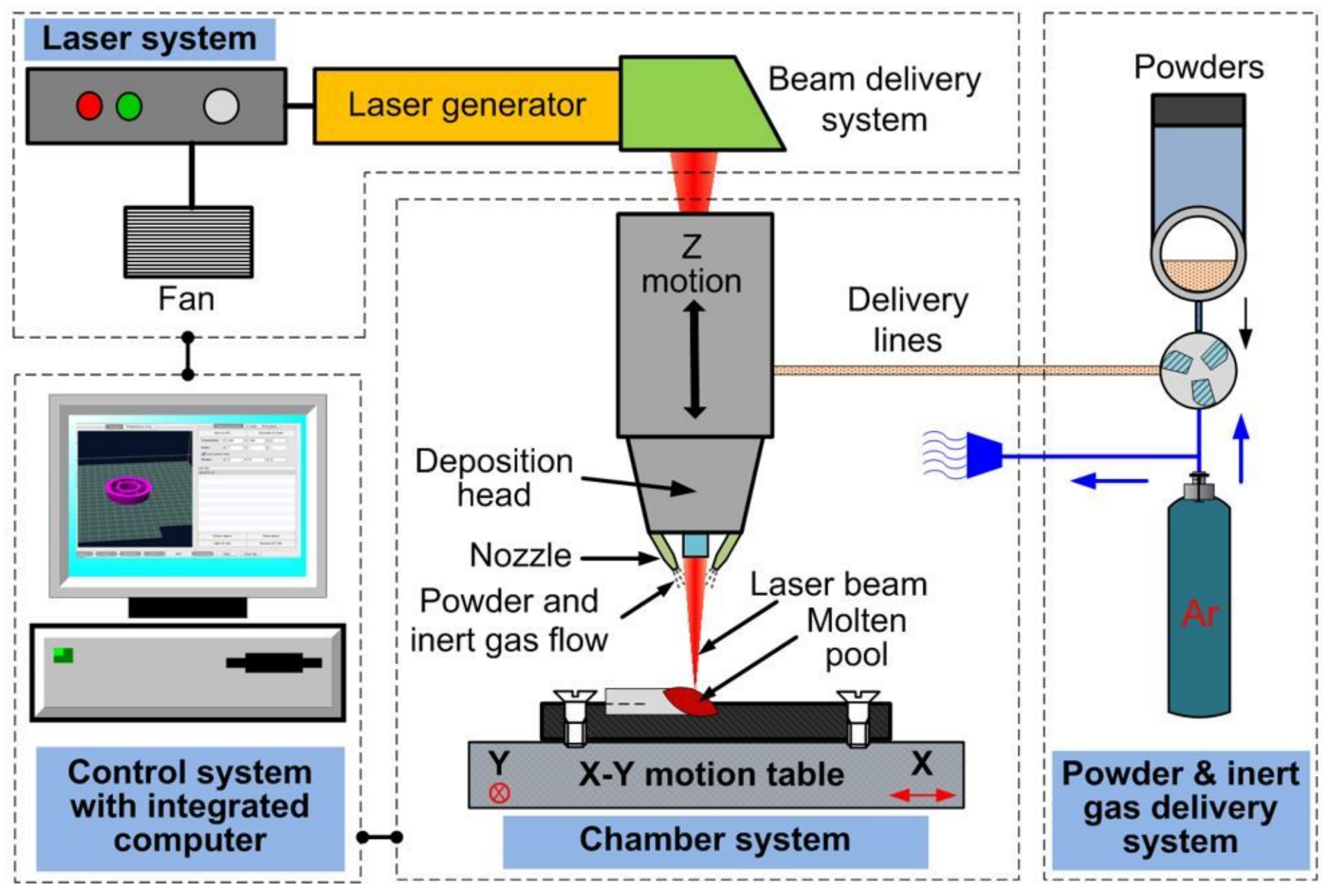

Figure 2

Experimental setup 


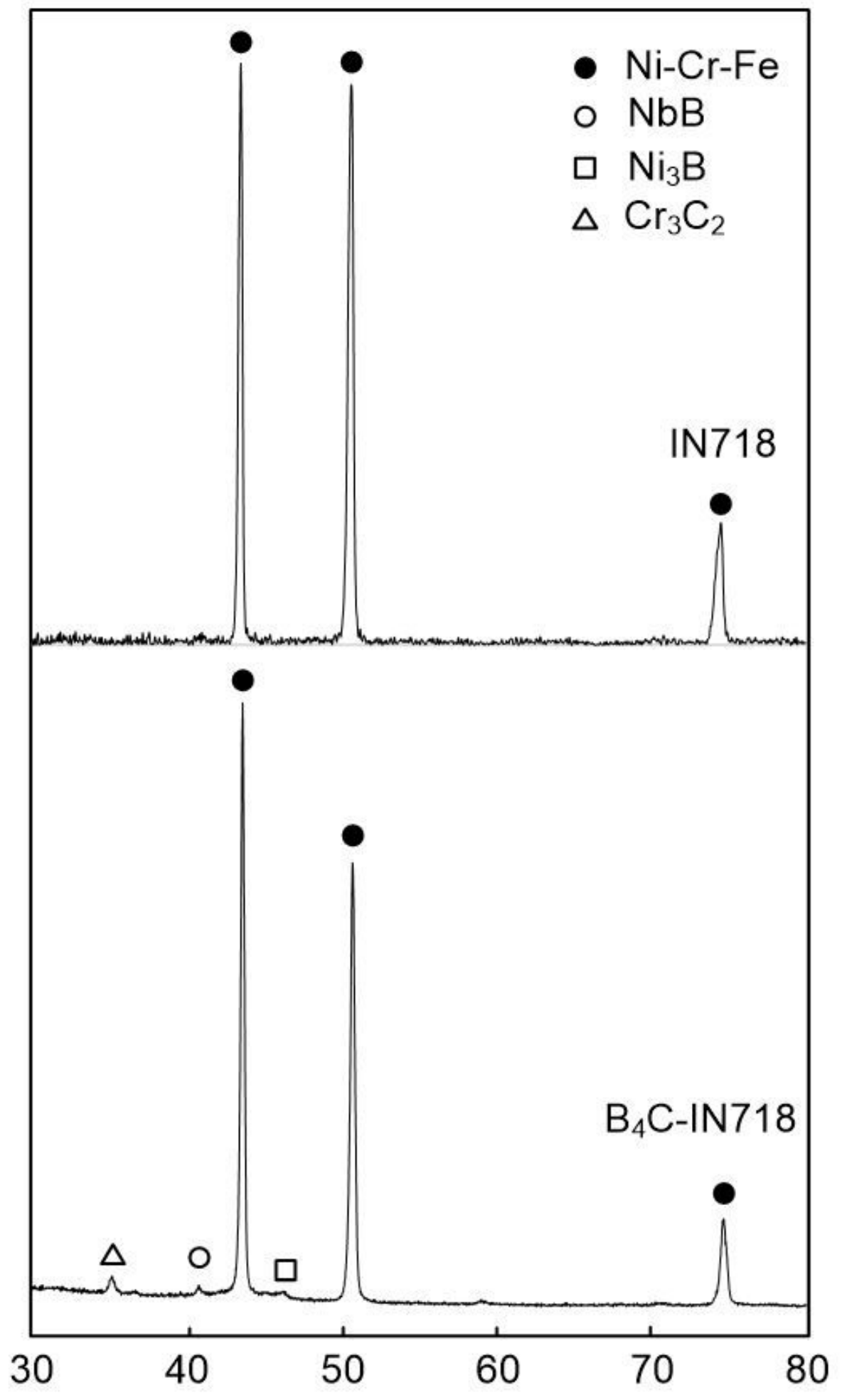

Figure 3

The phase composition of laser DED fabricated Inconel 718 coatings and $B_{4}$ C-Inconel 718 coatings. 
(a)

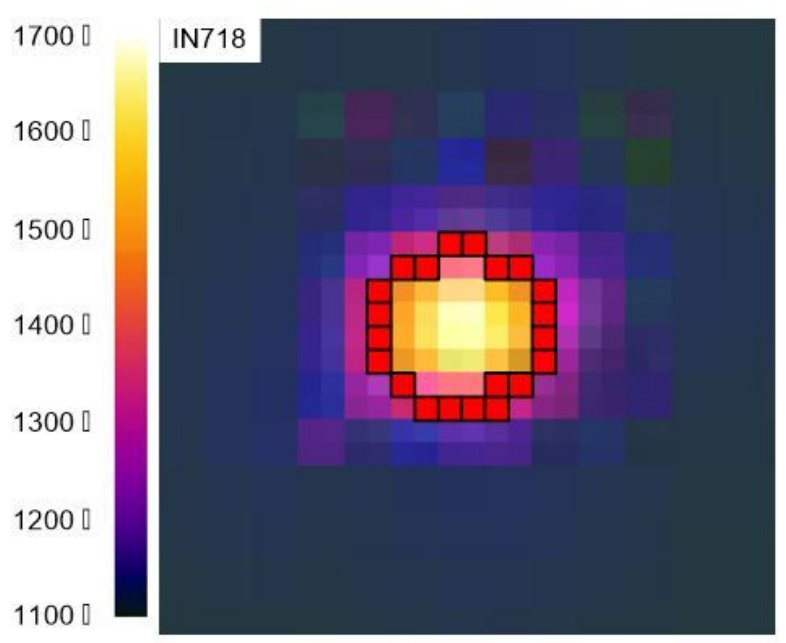

(b)

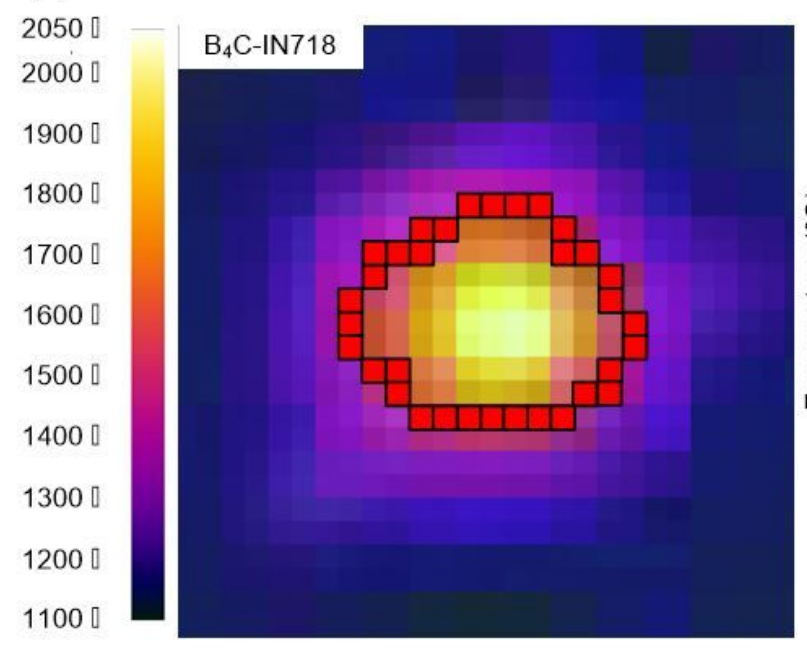

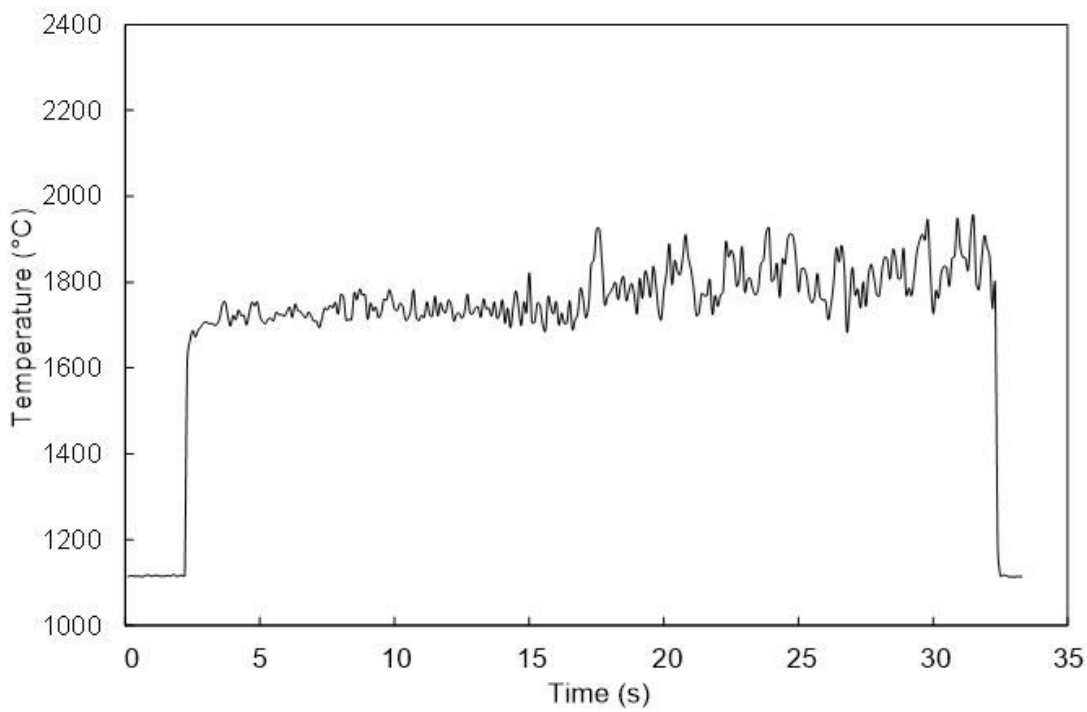

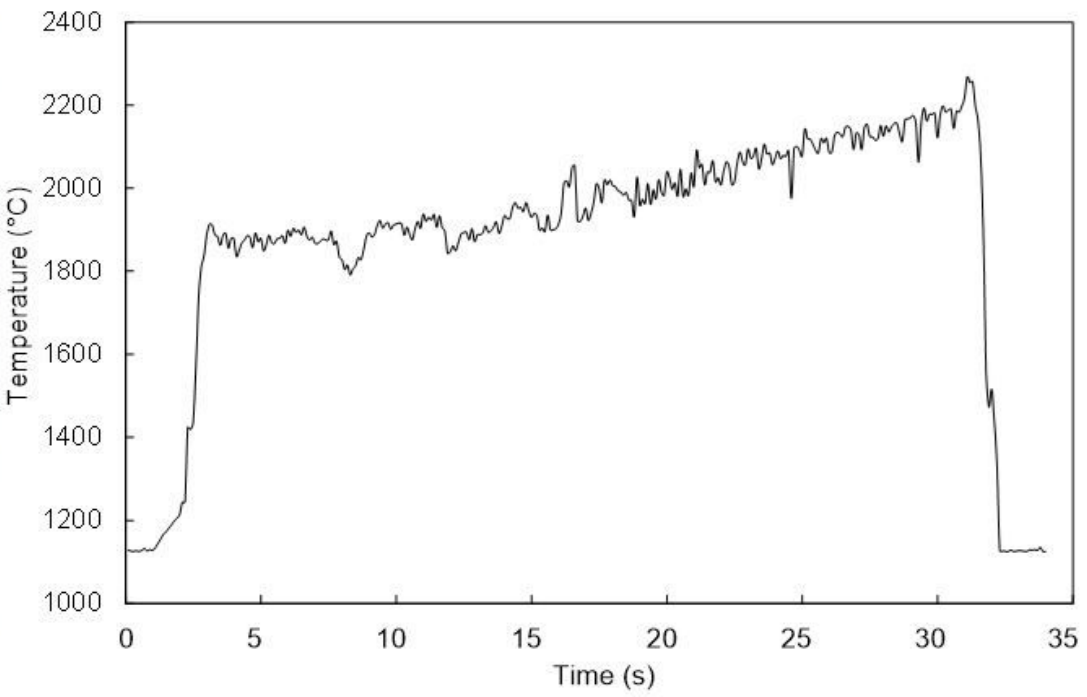

\section{Figure 4}

Molten pool size and maximum temperature: (a) Inconel 718 and (b) $\mathrm{B}_{4} \mathrm{C}$-Inconel 718 

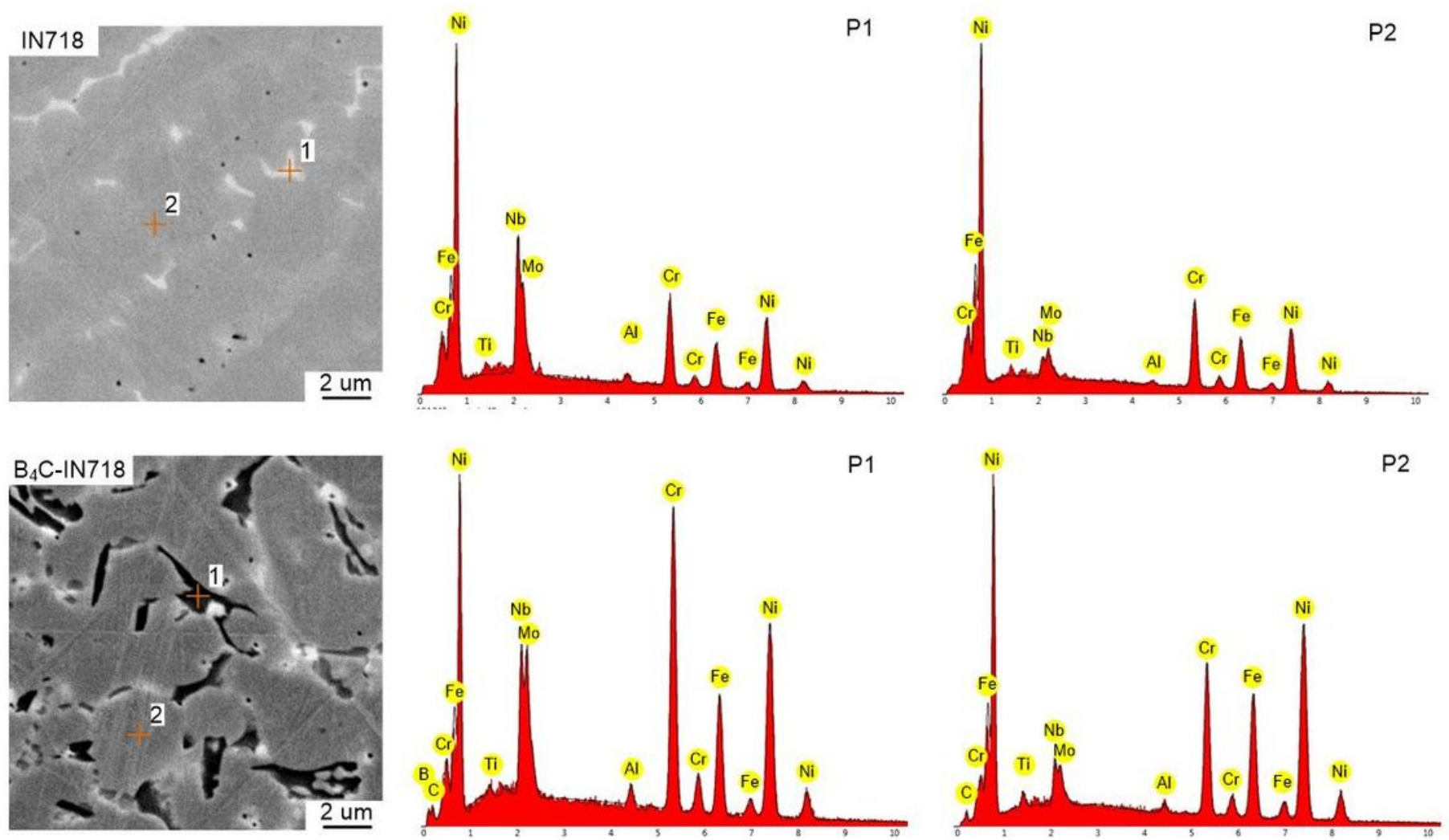

Figure 5

Element composition of laser DED fabricated Inconel 718 coatings and $\mathrm{B}_{4} \mathrm{C}-$-Inconel 718 coatings 

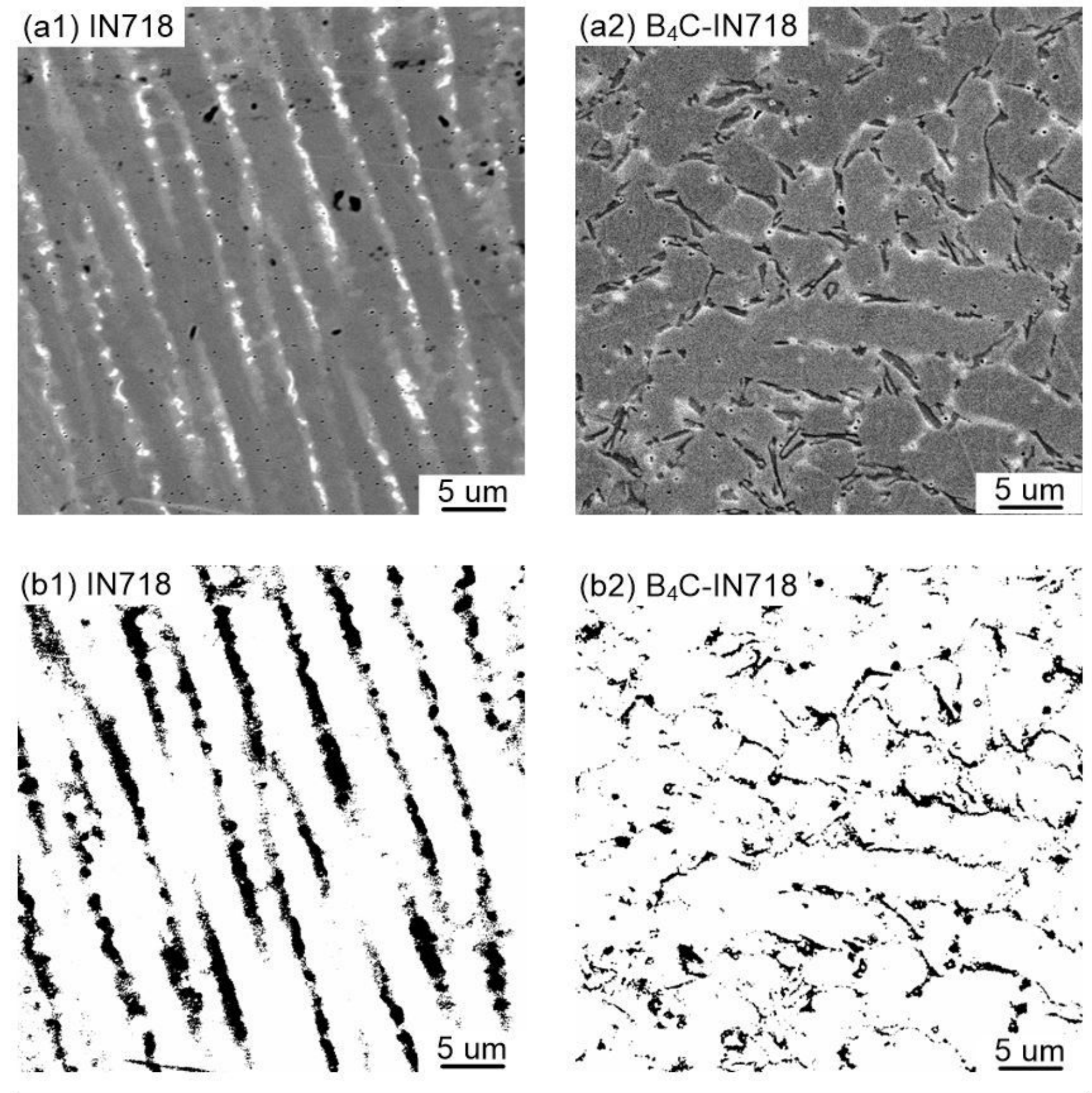

Inconel 718

B4C-Inconel 718

$17.742 \%$ Laves phase

$6.396 \%$ Laves phase

Figure 6

Microstructure of laser DED fabricated Inconel 718 coatings and $\mathrm{B}_{4} \mathrm{C}$-Inconel 718 coatings. * The Laves phase was shown as the black regions in (b1) Inconel 718 and (b2) B4C-Inconel 718 
(a)
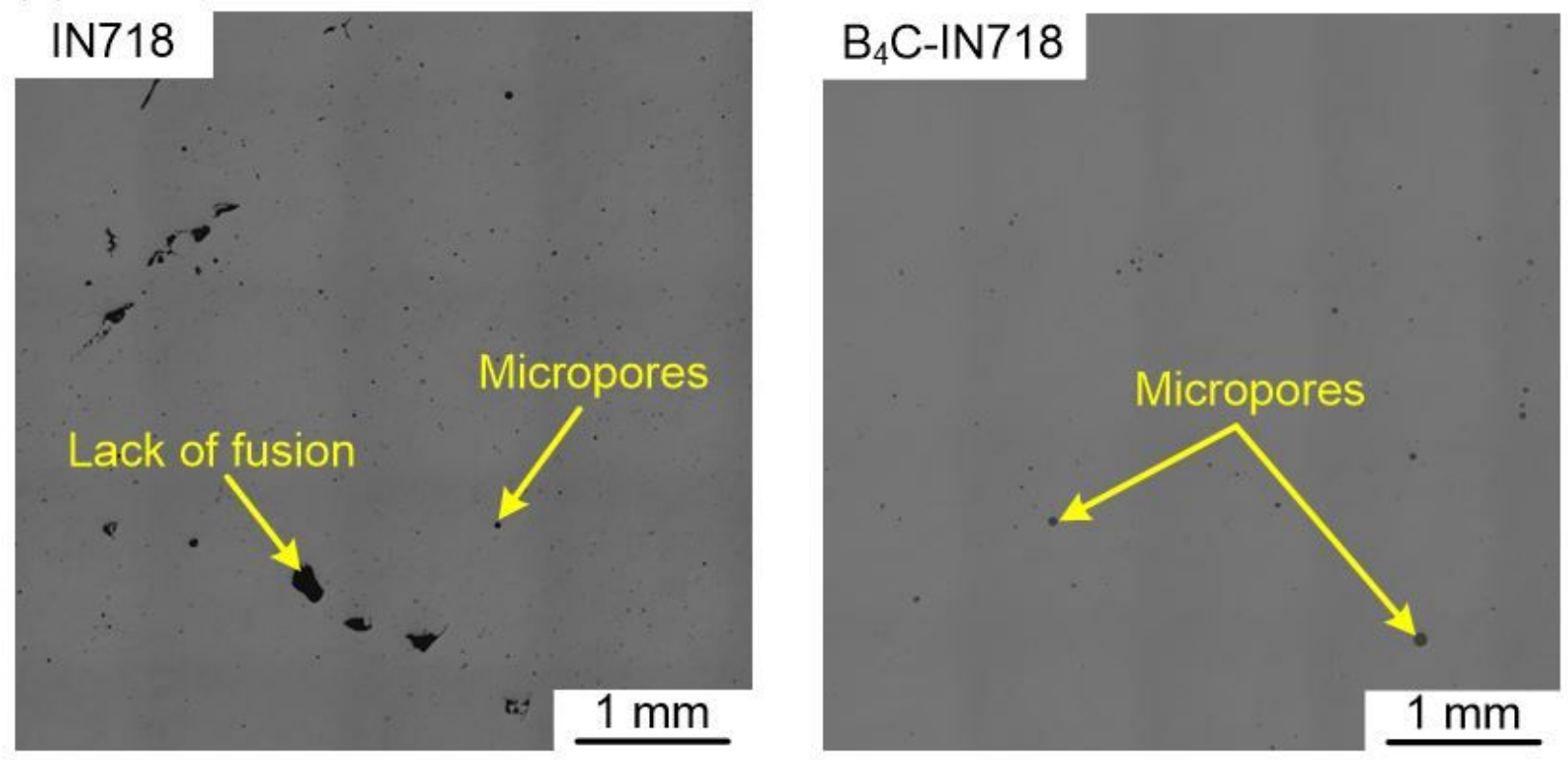

(b)

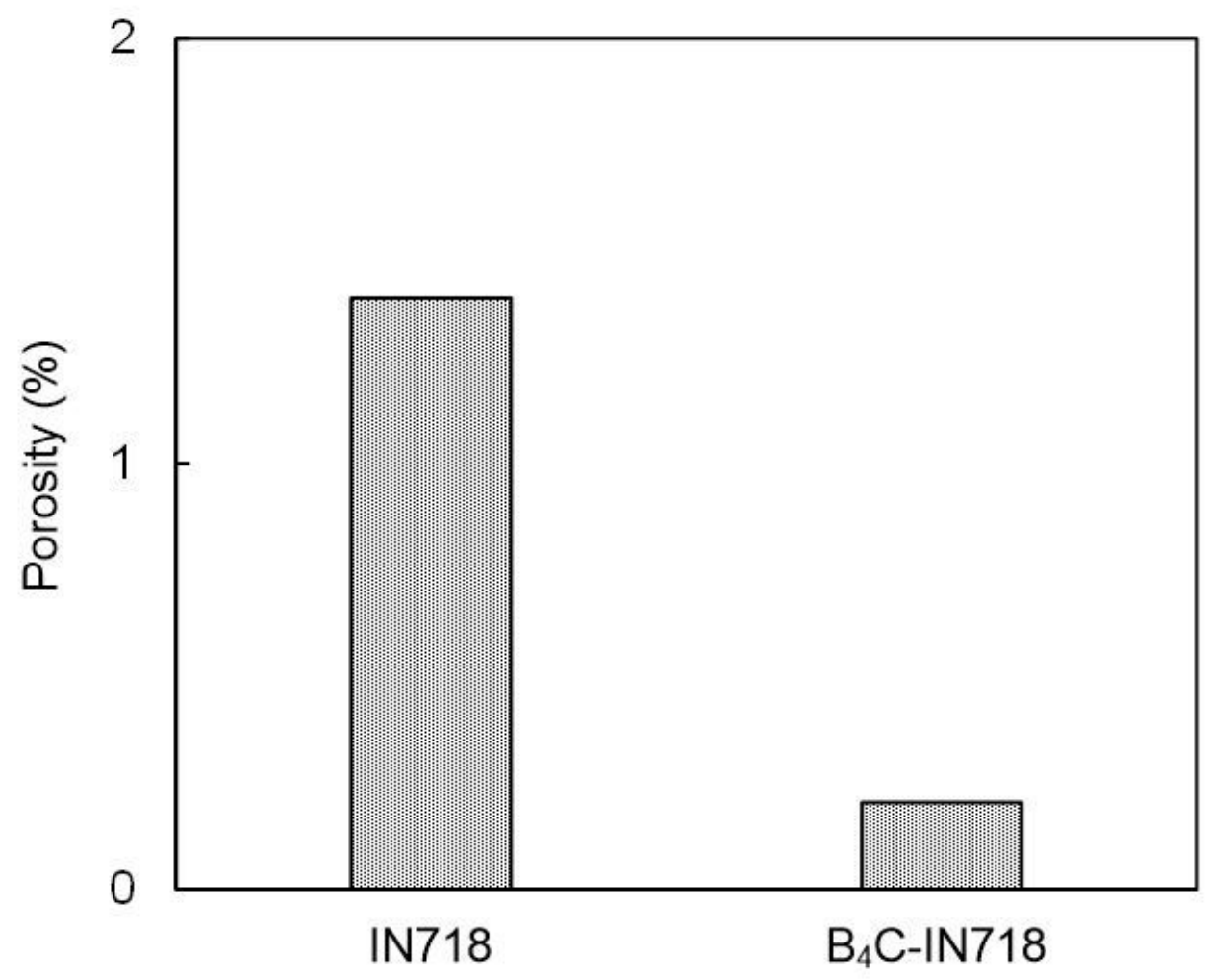

Figure 7

Porosity of laser DED fabricated Inconel 718 coatings and $\mathrm{B}_{4}$ C-Inconel 718 coatings: (a) optical microscope image and (b) porosity values 
(a)

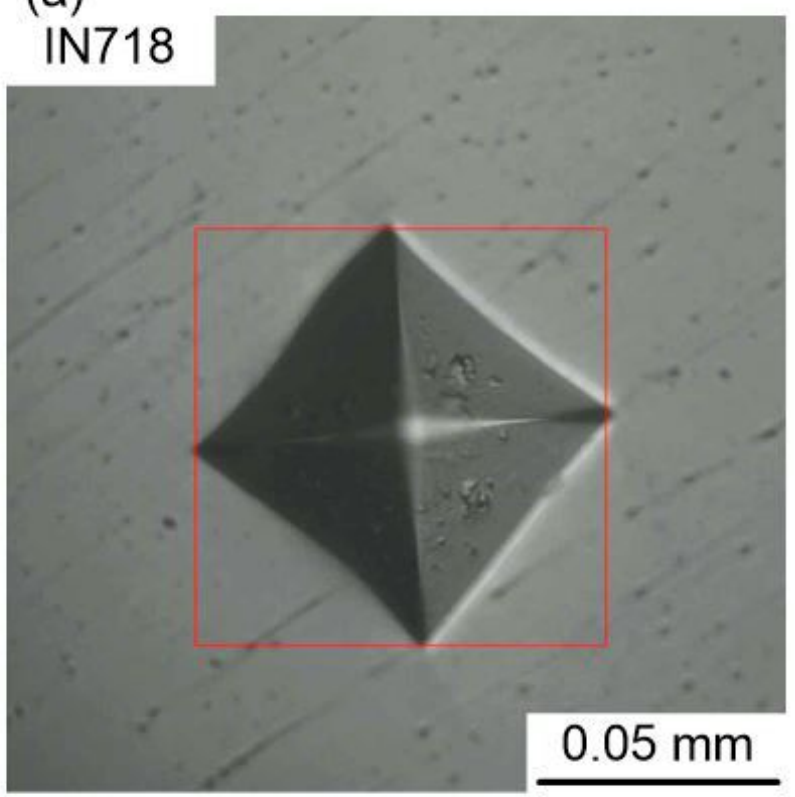

\section{$\mathrm{B}_{4} \mathrm{C}-\mathrm{IN} 718$}

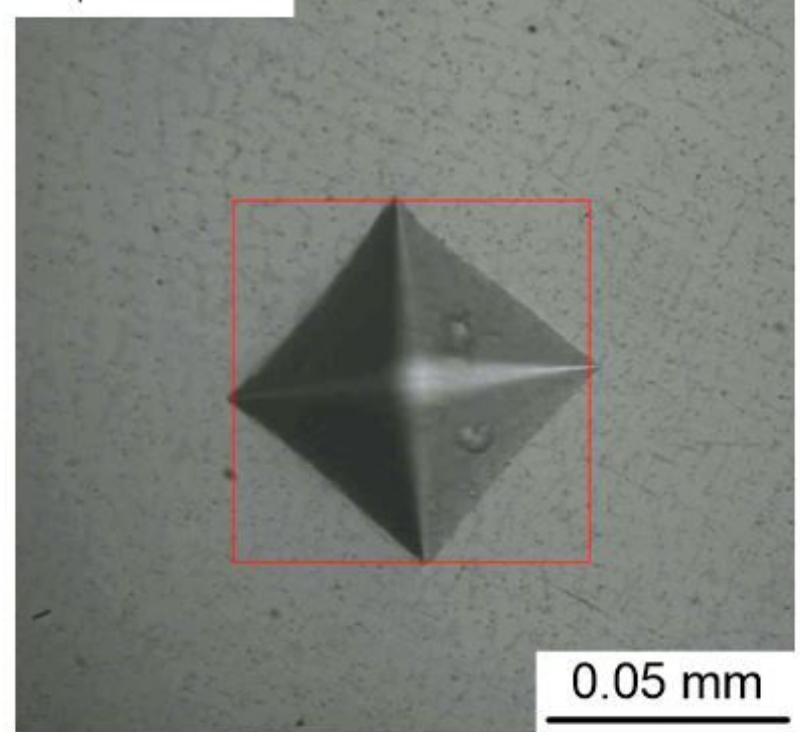

(b)

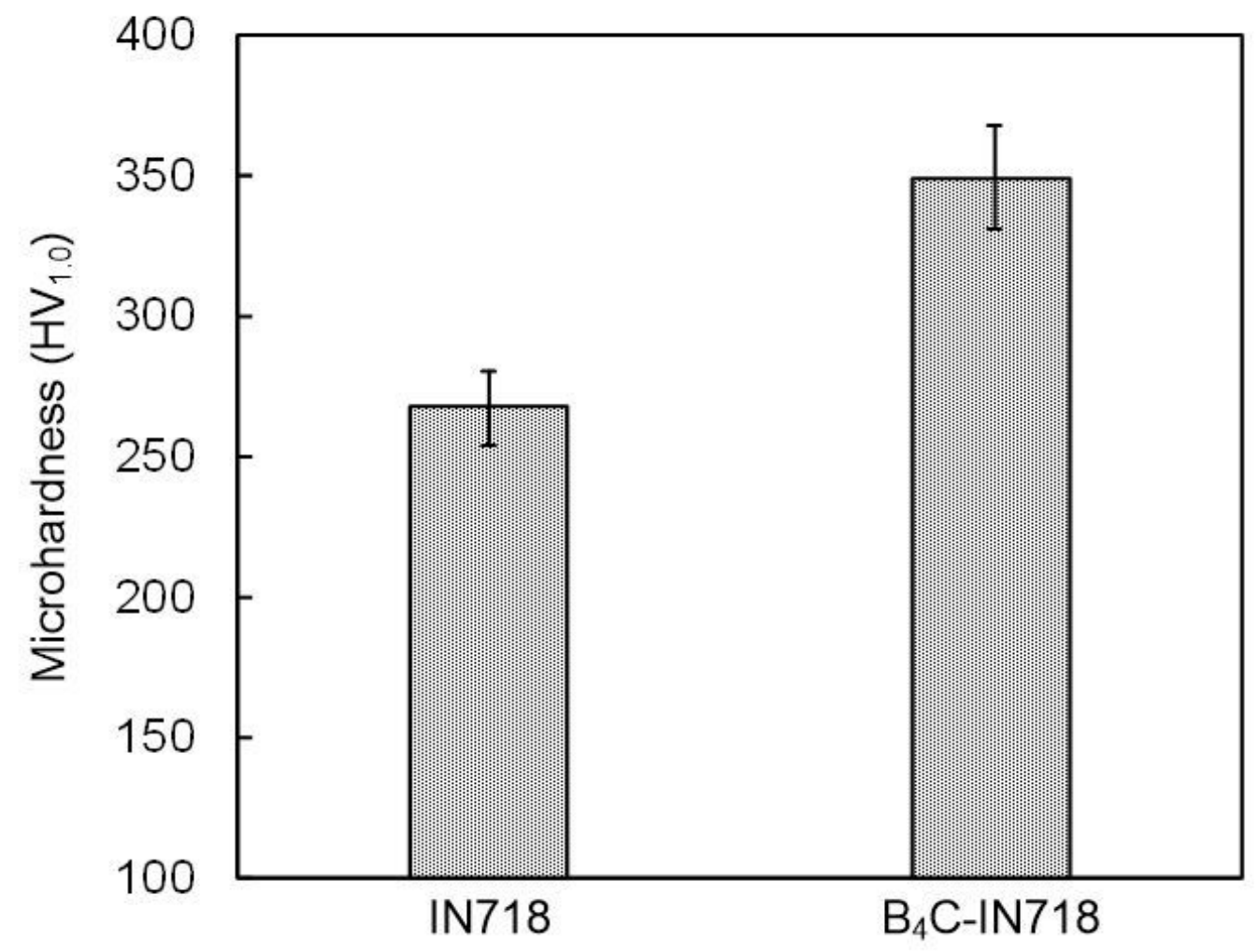

Figure 8

Microhardness of laser DED fabricated Inconel 718 coatings and $\mathrm{B}_{4} \mathrm{C}$-Inconel 718 coatings: (a) optical microscope image and (b) microhardness values 

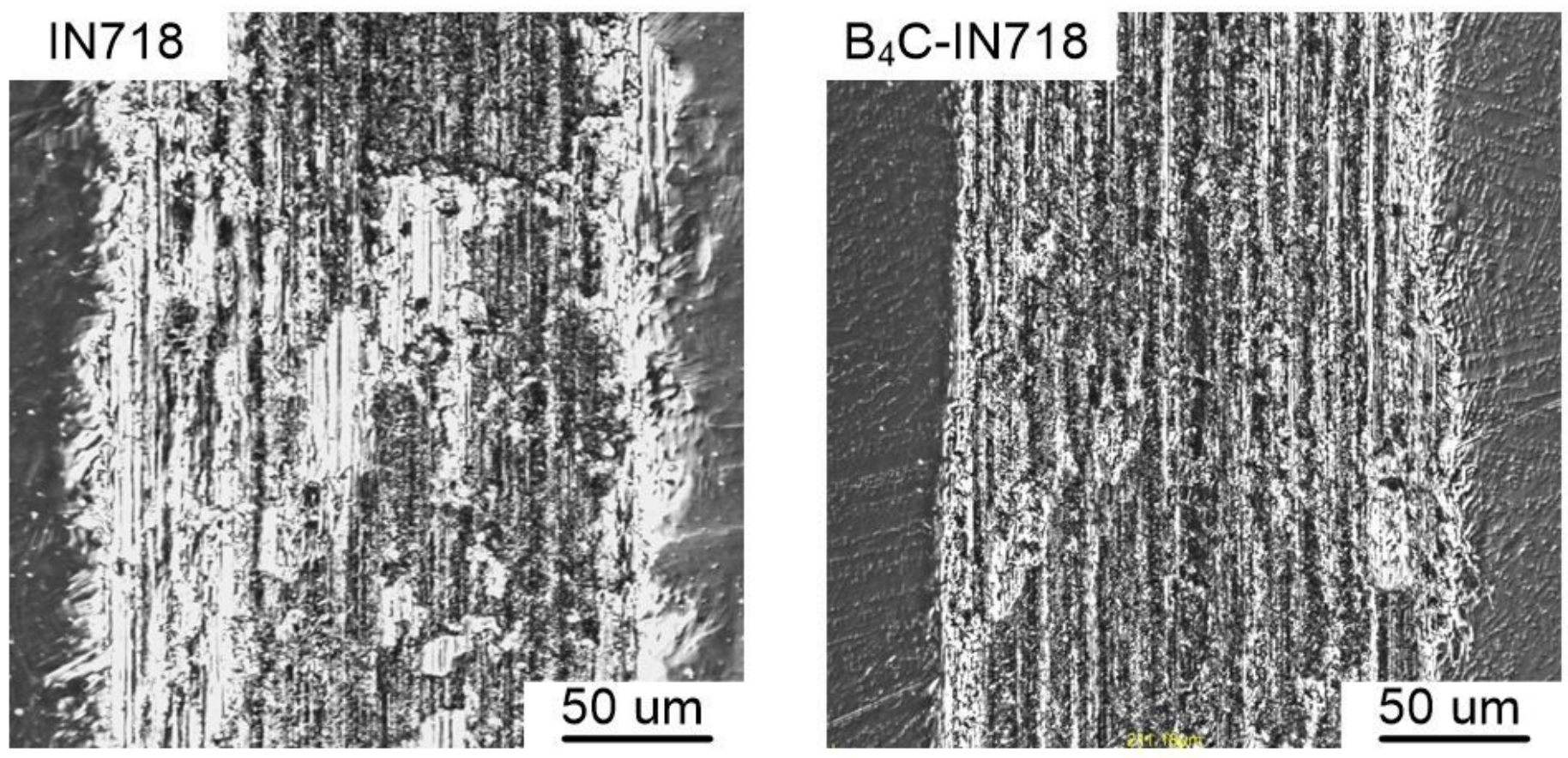

Figure 9

Worn surface morphologies of laser DED fabricated Inconel 718 coatings and $\mathrm{B}_{4} \mathrm{C}$-Inconel 718 coatings 


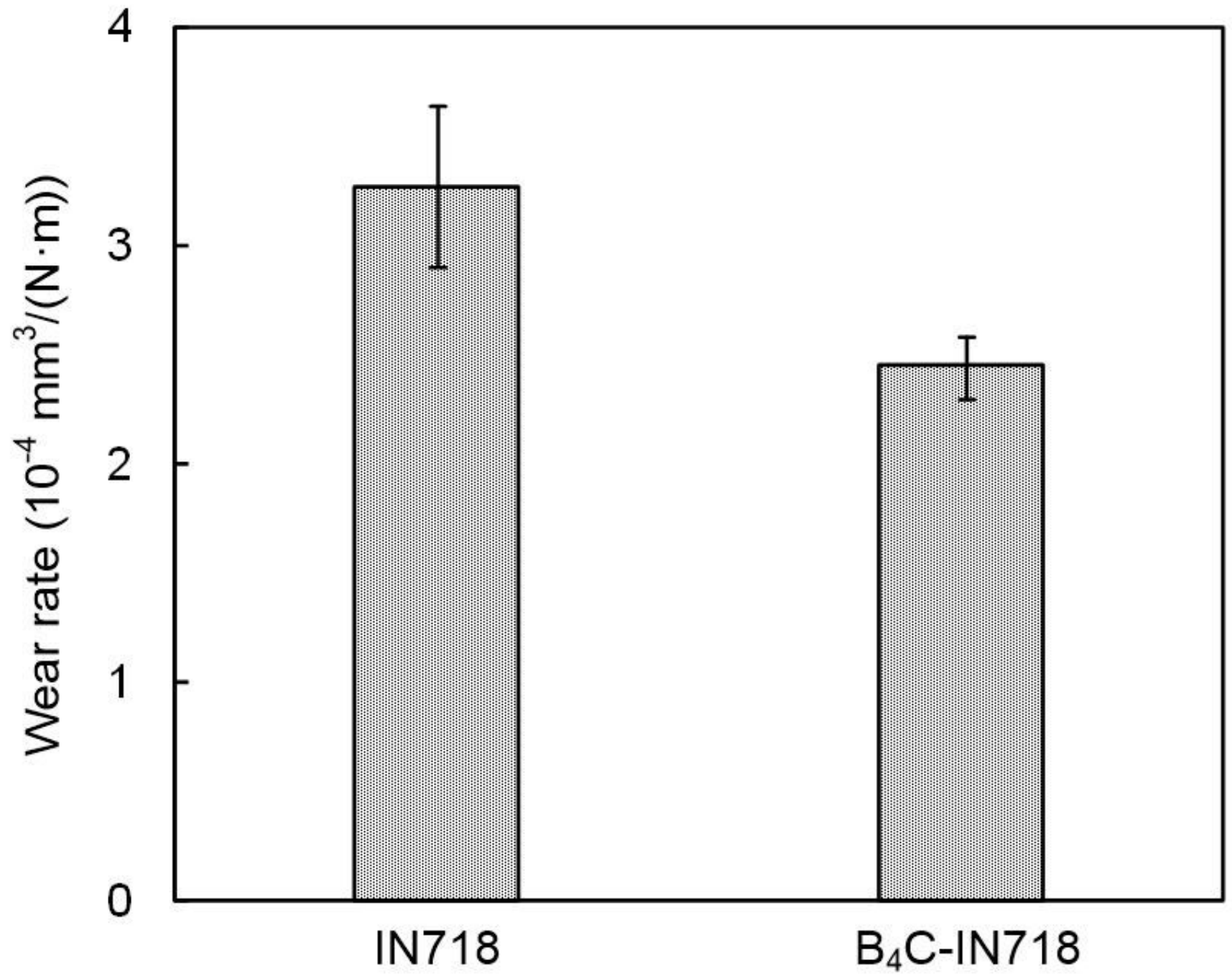

Figure 10

Wear resistance of laser DED fabricated Inconel 718 coatings and $\mathrm{B}_{4} \mathrm{C}-$-Inconel 718 coatings 